Fracture and Structural Integrity: ten years of Frattura ed Integrità Strutturale'

\title{
Mechanical and fracture properties of particleboard
}

\author{
Liviu Marsavina \\ Politehnica University of Timisoara, Department of Mechanics and Strength of Materials, 300222 Timisoara, Romania \\ liviu.marsavina@upt.ro
}

\section{Ion Octavian Pop}

Universite de Limoges, GC2D, EA 3178, Egletons F-19300, France

PFT Bois-Construction du Limousin, Egletons F-19300, France

ion-octavian.pop@unilim.fr

\section{Emanoil Linul}

Politehnica University of Timisoara, Department of Mechanics and Strength of Materials, 300222 Timisoara, Romania emanoil.linul@upt.ro,bttps://orcid.org/0000-0001-9090-8917

\begin{abstract}
Particleboard (PB) are wood-based composites with fine wood fibers bound together by a small amount of polymeric adhesive, widely used in furniture industry and civil engineering. PB plates can be painted, laminated or veneered, and have good dimensional stability and load bearing capacity when properly designed. However, the deformation and fracture of such elements create malfunctions of structures made of MDF. This paper presents experimental results obtained for three point bending (TPB) tests, mode I and mode II fracture toughness. The bending tests were carried on rectangular specimens, while the fracture toughness tests were performed on Single Edge Notched Bend (SENB) specimens for mode I, respectively on Compact Shear (CS) specimens for mode II loadings. Digital Image Correlation technique allows the determination of the Crack Relative Displacement Factor and estimation of the Energy Release Rate.
\end{abstract}

KEYwORDS. Particleboard; Fracture toughness; Digital Image Correlation.

\section{OPEN@ACCESS}

Citation: Marsavina, L., Pop, O., Linul, E., Mechanical and fracture properties of particleboard, Frattura ed Integrità Strutturale, 47 (2019) 266-276.

Received: 23.08 .2018

Accepted: 08.10 .2018

Published: 01.01.2019

Copyright: (C) 2018 This is an open access article under the terms of the CC-BY 4.0, which permits unrestricted use, distribution, and reproduction in any medium, provided the original author and source are credited.

\section{INTRODUCTION}

$\mathrm{P}$ articleboard (PB) represent a class of wood-based composite with fine wood fibers bound together by a small amount of polymeric adhesive. Their main applications are in furniture industry and civil engineering [1]. PB plates can be painted, laminated or veneered, and have good dimensional stability and load bearing capacity when 
properly designed [2]. However, the deformation and fracture of such elements create malfunctions of structures made of PB.

Different studies on bending properties of PB were published. In [3] design requirements for PB and Medium Density Fiberboard (MDF) plates under different loading conditions are presented. The performance of PB beams under four point bending are presented in [4]. The effect of different types of coatings on the strength and stiffness of PB are investigated in [5]. Kulman et al. [6] studied the effect of density and temperature on modulus of rupture and modulus of elasticity of $\mathrm{PB}$ and MDF.

The fracture behavior of wood and its composites is reviewed by Stanzl-Tschegg and Navi [7]. However, only a few studies investigates the fracture toughness of PB [8-10]. The same like in the case of MDF, different values of fracture toughness were obtained: Matsumoto and Nairn [11] $2.57 \mathrm{MPa} \cdot \mathrm{m}^{1 / 2}$ for density of $609 \mathrm{~kg} / \mathrm{m}^{3}$, respectively $3.77 \mathrm{MPa} \cdot \mathrm{m}^{1 / 2}$ for density of $769 \mathrm{~kg} / \mathrm{m}^{3}$ using Compact Tension (CT) specimens, while for wedge splitting specimens and a density of $710 \mathrm{~kg} / \mathrm{m}^{3} \mathrm{Niemz}$ et al. [12] obtained $1.81 \mathrm{MPa} \cdot \mathrm{m}^{1 / 2}$. Fewer investigations were carried out on mixed mode fracture toughness of PB and MDF; [13].

Today, several fracture approaches such as the Stress Intensity Factor (SIF) [14-16], the Crack Relative Displacement Factor (CRDF) [17-20] or the energy release rate [21-24] allow expressing fracture criteria. It should also be noted that usually the damage level could be evaluated from a local approach based on the mechanical fields assigned by the crack tip singularity or by a global approach using the mechanical fields far to the crack tip singularity. Starting from this analysis, in the present study, a formalism based on the SIF and the CRDF was applied to evaluate the fracture process.

As will be shown latter the CRDF allows definition of the kinematic state around to the crack tip. As defined by Dubois et al. [17, 18], Pop et al. [19] and Jamaaoui et al. [25], the crack opening state represents the relative displacement between two points positioned on the upper and the lower crack flanks. Its evaluation can be performed directly from the experimental measurements. Associated more often to full fields techniques, the optical methods can be easily applied to observe and to analyze the fracture process. Today, several optical techniques and methods are developed in order to measure the different fracture properties. Among these methods, we remind here: interferometry, stereo correlation, moiré, photoelasticity, Digital Image Correlation (DIC) or mark- tracking methods [24, 26-32]. Nevertheless, their application to analyze the fracture process depends on the observation scale and the environmental boundary conditions (i.e. laboratory or in-situ). Concerning the characterization of mechanical and fracture properties of PB the DIC and the mark-tracking methods seem to be the better. For this purpose, the Crack Opening Displacement was measured by means the DIC. Associated with optical full field methods the DIC allows measure of the bi-dimensional displacement and strain fields. The interest of this method lies in its possibility to perform the measurements without contact. Moreover, the studied zone, sometimes called the zone of interest, can be easily adapted to the analyze scale (i.e. local or global). Today several algorithms to perform the DIC in order to evaluate the fracture parameters are proposed [29-37]. In the present study, the analysis was performed using Correla software's, developed by PEM team of Pprim Institut of Poitiers [38-39]. The present paper presents the original results, obtained for two different densities and thicknesses of PB, for modulus of rupture, modulus of elasticity, the fracture toughness in mode I and predominantly mode II and the crack relative intensity factors.

\section{EXPERIMENTAL DETERMINATION OF MECHANICAL AND FRACTURE PROPERTIES}

\section{Materials}

7 ests were carried out on medium density PB with thicknesses of 16 and $25 \mathrm{~mm}$. The density was determined on each specimen resulting a mean density of $600( \pm 12) \mathrm{kg} / \mathrm{m}^{3}$ for the PB with $16 \mathrm{~mm}$ thickness, respectively 587 $( \pm 15) \mathrm{kg} / \mathrm{m}^{3}$ for the $\mathrm{PB}$ with $25 \mathrm{~mm}$ thickness. The specimens before testing were conditioned at $22 \pm 2^{\circ} \mathrm{C}$ room temperature and $65 \pm 5 \%$ relative air humidity.

\section{Bending tests}

The tests were performed on a Zwick Roell Z005 electromechanical universal testing machine under displacement control by setting the machine to $10 \mathrm{~mm} / \mathrm{min}$. During the test, the force versus deflection was measured by means of linear variable differential transformer (LVDT) position sensor $(-/+0.01 \mathrm{~mm})$ and a load cell of $5 \mathrm{kN}( \pm 5 \%)$. Rectangular specimens, Fig. 1, were adopted for the Three Point Bending tests, with dimensions $B$ (height) $\times B$ (width) $\times L$ (length) For $16 \mathrm{~mm}$ thickness the dimensions were $B=16 \mathrm{~mm}, L=250 \mathrm{~mm}$, and the span (distance between supports) $S=192 \mathrm{~mm}$ respectively for $25 \mathrm{~mm}$ thickness $B=25 \mathrm{~mm}, L=250 \mathrm{~mm}$, and $S=192 \mathrm{~mm}$. The test program consisted of four test series (two different thicknesses of PB plates of 16 and $25 \mathrm{~mm}$, respectively two orientations 1 and 2) with five tests in each 
series. Orientation 1 corresponds to an out-of-plane loading, and orientation 2 corresponds to an in-plane loading direction. Typical force - displacement curves are shown in Fig. 2. It could be observed that for orientation 1, which is the one most used for $\mathrm{PB}$, higher values of loads were obtained comparing with direction 2 and a quasi-brittle behavior

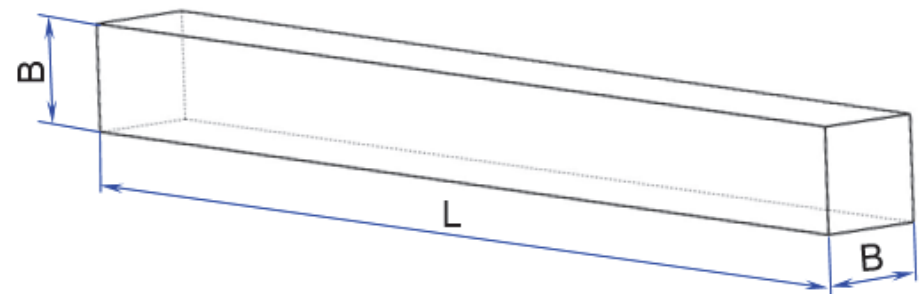

Figure 1: Three point bending specimen

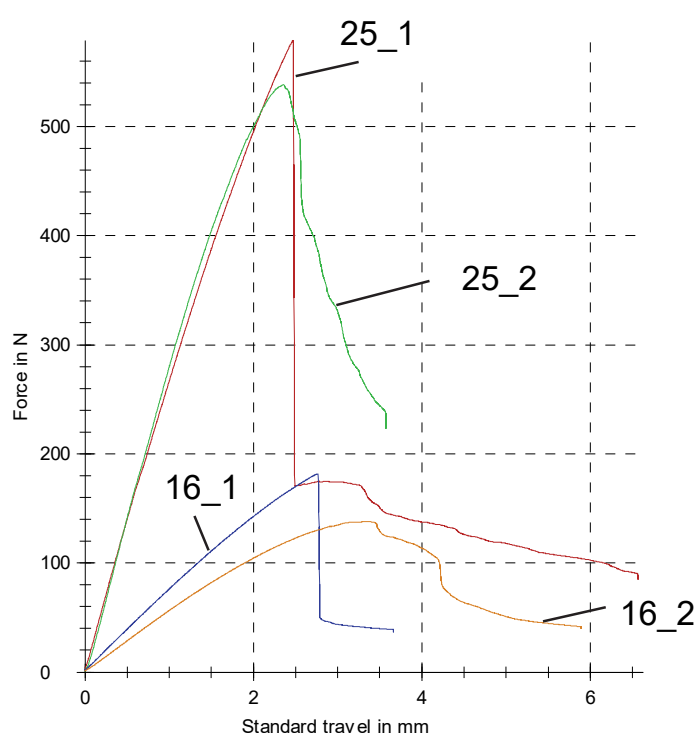

Figure 2: Typical force - displacement curves

Based on the EN 310 standard [40], the Modulus of Rupture (MOR) and Modulus of Elasticity (MOE) were determined. The three point bending results are shown in Fig. 3. It could be observed that the maximum values of MOR and MOE were obtained for direction 1 and $16 \mathrm{~mm}$ thickness PB: $11.5 \mathrm{MPa}$, respectively $1782 \mathrm{MPa}$. The obtained values are in accordance with those from literature for $\mathrm{PB}$, as follow: $11 \mathrm{MPa}$ for MOR and $1725 \mathrm{MPa}$ for MOE. In Fig. 3 boxes marked with 1 and 2 are related to sample orientation according to loading direction.

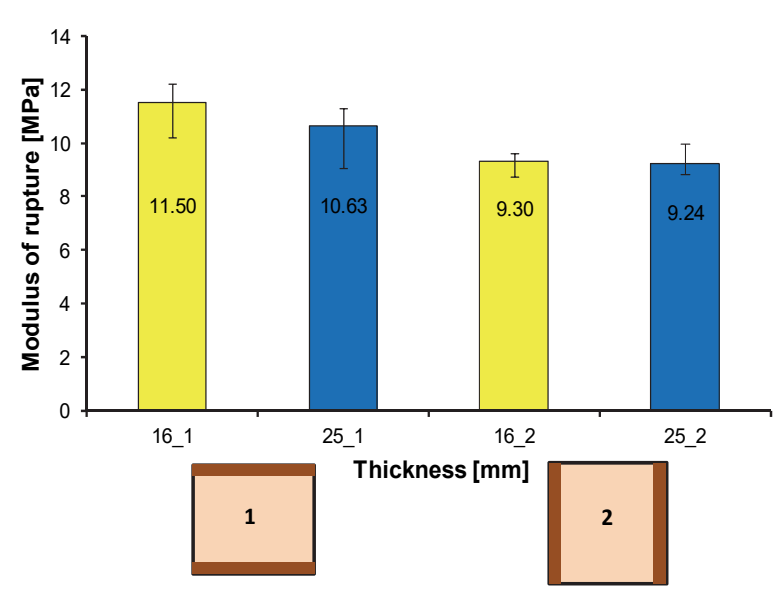

a. Modulus of rupture

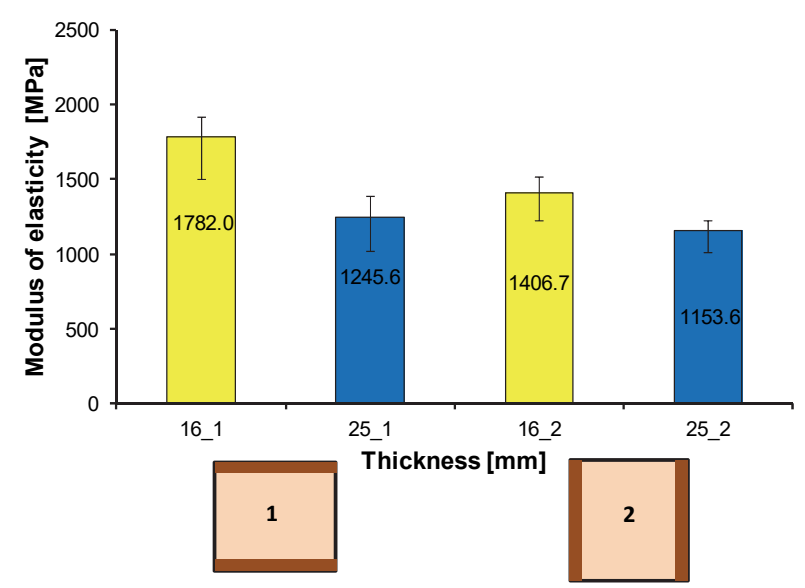

b. Modulus of elasticity

Figure 3: Mechanical properties of particleboard

\section{Mode I fracture toughness tests}

Mode I fracture toughness tests were carried out on Single Edge Notched Bend (SENB) specimens [41], Fig. 4a loaded in three point bending using Zwick Roell Z005, at room temperature, under displacement control with a loading speed of 10 $\mathrm{mm} / \mathrm{min}$. The maximum load $F_{\max }$ recorded during the tests was considered to calculate Mode I fracture toughness $\left(K_{I C}\right)$, given by Eq. (1): 


$$
K_{I C}=\frac{F_{\max }}{B W^{1 / 2}} f(a / W)
$$

with $W$ specimen width, $B=W / 2$ specimen thickness and $f(a / W)$ is dimensionless SIF for SENB specimens, calculated with the following [42]:

$$
f(a / W)=6 \sqrt{a / W} \frac{1.99-(a / W)(1-a / W)\left[2.15-3.93(a / W)+2.7(a / W)^{2}\right]}{(1+2 a / W)(1-a / W)^{3 / 2}} .
$$

\begin{tabular}{ccccccc}
\hline Specimen & $\begin{array}{c}\text { Thickness } \\
B[\mathrm{~mm}]\end{array}$ & $\begin{array}{c}\text { Width } \\
W[\mathrm{~mm}]\end{array}$ & $\begin{array}{c}\text { Crack } \\
\text { Length } \\
a[\mathrm{~mm}]\end{array}$ & $\begin{array}{c}\text { Maximum } \\
\text { load } \\
F_{\text {max }}[\mathrm{N}]\end{array}$ & $\begin{array}{c}\text { Fracture } \\
\text { toughness } \\
K_{I C}\left[\mathrm{MPa} \cdot \mathrm{m}^{1 / 2}\right]\end{array}$ & $\begin{array}{c}\text { Mean Fracture } \\
\text { toughness } \\
K_{I C}\left[\mathrm{MPa} \cdot \mathrm{m}^{1 / 2}\right]\end{array}$ \\
I.1 & 23.8 & 50.1 & 24.6 & 466 & 0.868 & \\
I.2 & 23.6 & 50.1 & 24.5 & 465 & 0.868 & 0.841 \\
I.3 & 23.6 & 50.1 & 24.5 & 454 & 0.847 & \\
I.4 & 23.6 & 50.1 & 24.5 & 417 & 0.778 & \\
I.5 & 23.6 & 50.1 & 24.5 & 452 & 0.843 & \\
\hline I.6 & 16.3 & 32 & 17.8 & 178 & 0.784 & \\
I.7 & 16.1 & 32 & 16.8 & 154 & 0.618 & \\
I.8 & 16.2 & 32 & 18.8 & 149 & 0.740 & \\
I.9 & 16.1 & 32 & 17.8 & 153 & 0.682 & \\
I.10 & 16.1 & 32 & 17.5 & 198 & 0.855 & \\
\hline
\end{tabular}

Table 1: Mode I fracture toughness results

The specimen dimensions, maximum load and mode I fracture toughness are summarized in Tab. 1. It could be observed that the maximum value of $K_{I C}=0.841 \mathrm{MPa} \cdot \mathrm{m}^{1 / 2}$ was obtained for the $25 \mathrm{~mm}$ PB thickness. On contrary, the mode I fracture toughness for $16 \mathrm{~mm}$ thickness was $0.736 \mathrm{MPa} \cdot \mathrm{m}^{1 / 2}$.

\section{Mode II fracture toughness tests}

Compact Shear (CS) specimens [43], Fig. 4b, were used for mode II fracture toughness determination. Tests were performed on a $100 \mathrm{kN}$ A009 (TC100) universal testing machine, at room temperature and using $10 \mathrm{~mm} / \mathrm{min}$ displacement control. Maximum load was used to estimate the mode I and mode II stress intensity factors. The SIFs solutions could be expressed on the form:

$$
K_{i C}=\frac{F_{\max }}{H B} \sqrt{a} f_{i}(a / W), \quad i=I, I I
$$

with $B$ as the specimen thickness, a as crack length and $H$ as specimen width. A numerical calibration of the specimen was performed earlier by Petrova et. al. [44] using finite element analysis in order to determine the non-dimensional SIFs $f_{i}(a / W)$, resulting:

$$
\begin{aligned}
& f_{I}(a / W)=2.472(a / W)^{4}-1.784(a / W)^{3}+1.135(a / W)^{2}-0.213(a / W)+0.295 \\
& f_{I I}(a / W)=6.416(a / W)^{4}-11.154(a / W)^{3}+8.992(a / W)^{2}-3.667(a / W)+1.01
\end{aligned}
$$

It should be noted that even if the applied load produce shear in front of the crack, a small amount of mode I still exist at the crack tip [44], so the fracture thoughness could be expressed using an effective SIF value: 


$$
K_{e f f}=\sqrt{K_{I}^{2}+K_{I I}^{2}}
$$

Tab. 2 presents the specimen dimensions, maximum load, the mode I, mode II and effective SIFs. A higher value of $K_{\text {eff }}=$ $0.785 \mathrm{MPa} \cdot \mathrm{m}^{1 / 2}$ was obtained for the PB with $25 \mathrm{~mm}$ thickness comparing with the PB of $16 \mathrm{~mm}$ thickness, $K_{\text {eff }}=0.631$ $\mathrm{MPa} \cdot \mathrm{m}^{1 / 2}$.

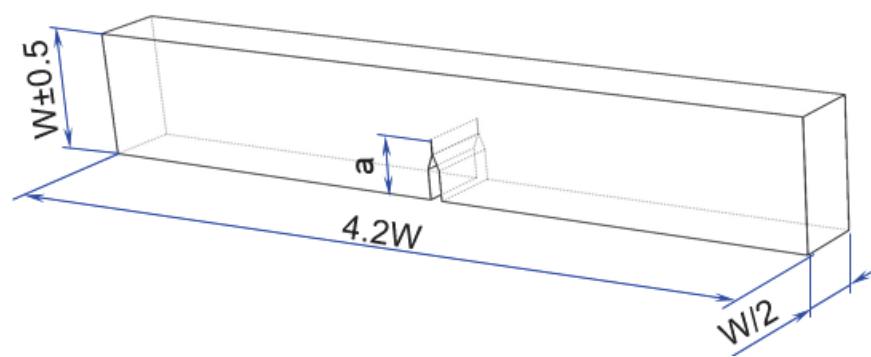

a. Single Edge Notch Bend

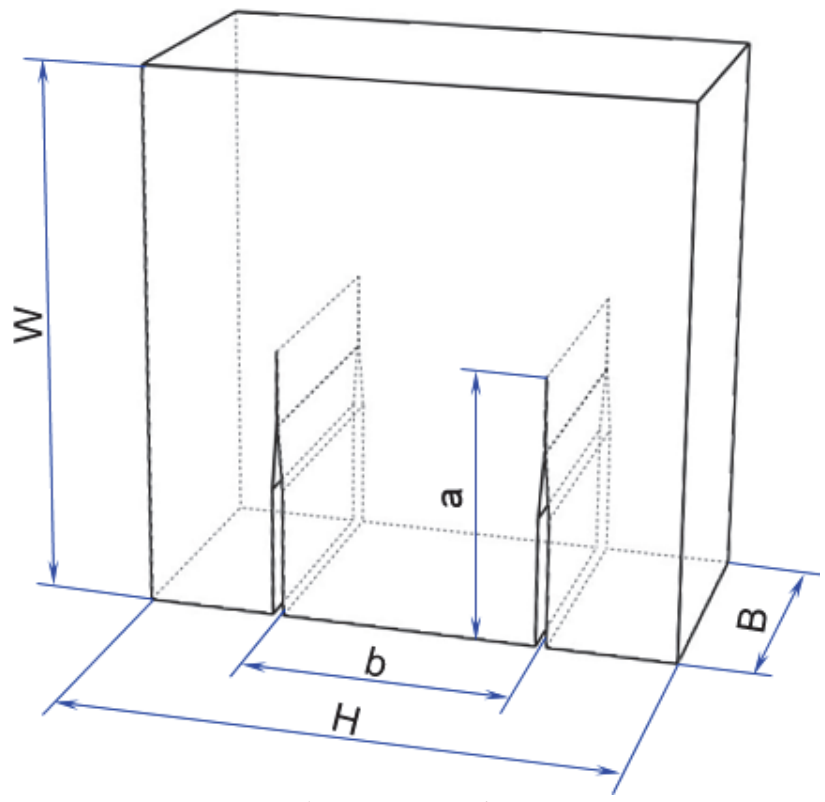

b. Compact Shear

Figure 4: Test specimens for mode I and mode II fracture toughness determination.

\begin{tabular}{cccccccccc}
\hline Specimen & $\begin{array}{c}B \\
{[\mathrm{~mm}]}\end{array}$ & $\begin{array}{c}W \\
{[\mathrm{~mm}]}\end{array}$ & $\begin{array}{c}H \\
{[\mathrm{~mm}]}\end{array}$ & $\begin{array}{c}a \\
{[\mathrm{~mm}]}\end{array}$ & $\begin{array}{c}F_{\max } \\
{[\mathrm{N}]}\end{array}$ & $\begin{array}{c}K_{I} \\
{\left[\mathrm{MPa} \cdot \mathrm{m}^{1 / 2}\right]}\end{array}$ & $\begin{array}{c}K_{I I} \\
{\left[\mathrm{MPa} \cdot \mathrm{m}^{1 / 2}\right]}\end{array}$ & $\begin{array}{c}K_{\text {eff }} \\
{\left[\mathrm{MPa} \cdot \mathrm{m}^{1 / 2}\right]}\end{array}$ & $\begin{array}{c}\text { Mean } K_{\text {eff }} \\
{\left[\mathrm{MPa} \cdot \mathrm{m}^{1 / 2}\right]}\end{array}$ \\
II.1 & 16.4 & 50.3 & 76.6 & 25.0 & 3110 & 0.101 & 0.565 & 0.574 & \\
II.2 & 16.4 & 50.0 & 76.0 & 25.0 & 3470 & 0.113 & 0.630 & 0.640 & \\
II.3 & 16.4 & 51.1 & 76.0 & 25.0 & 3700 & 0.120 & 0.672 & 0.682 & 0.631 \\
II.4 & 16.4 & 49.3 & 76.3 & 25.6 & 3050 & 0.091 & 0.532 & 0.540 & \\
II.5 & 16.4 & 50.0 & 76.0 & 25.0 & 3900 & 0.127 & 0.708 & 0.720 & \\
\hline II.6 & 24 & 75.0 & 100 & 48.5 & 5911 & 0.198 & 0.826 & 0.850 & \\
II.7 & 24 & 76.0 & 100 & 48.5 & 5189 & 0.174 & 0.725 & 0.746 & 0.785 \\
II.8 & 24 & 76.2 & 100 & 49.2 & 5788 & 0.194 & 0.810 & 0.833 & 0.803 \\
II.9 & 24 & 75.0 & 100 & 48.7 & 5587 & 0.187 & 0.781 & 0.693 & \\
II.10 & 24 & 75.4 & 100 & 47.7 & 4814 & 0.162 & 0.674 & 0.693 & \\
\hline
\end{tabular}

Table 2: Mode II fracture toughness results

The obtained results are represented in the fracture envelope plot $K_{\text {II }} / K_{\text {IC }}$ versus $K_{I} / K_{\text {IC }}$ side by side with the analytical predictions of Maximum Tensile Stress (MTS) [45, 46], Maximum Energy Release Rate (Gmax) [47, 48] and Minimum Strain Energy Density (SED) [49, 50]. From Fig. 5, it could be observed that the MTS and SED criteria fits better with the experimental results. 


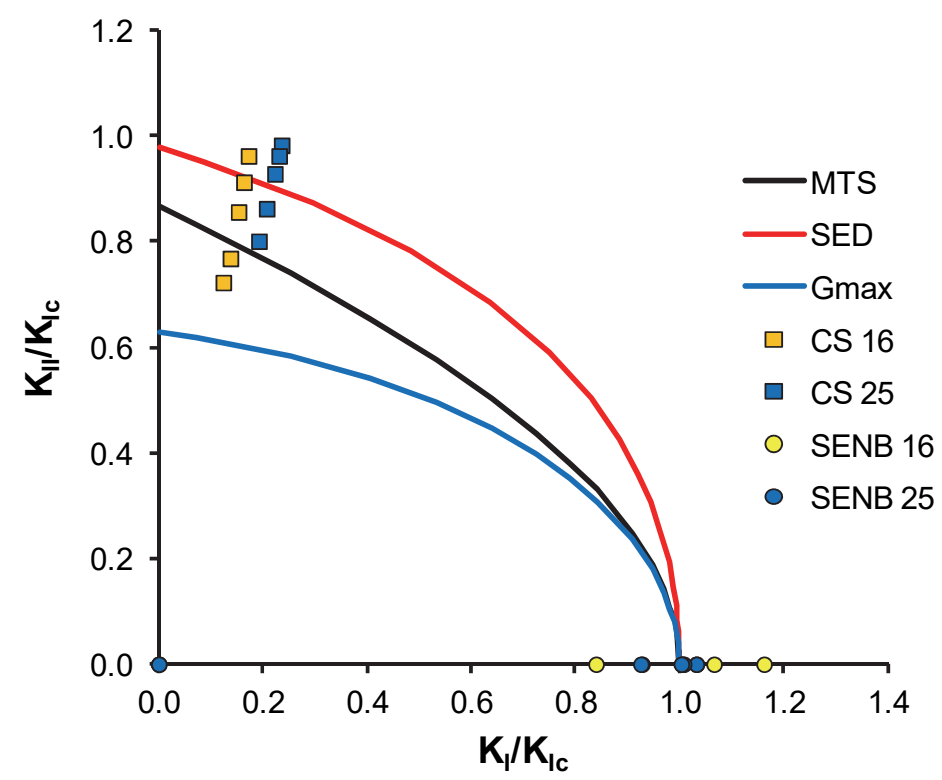

Figure 5: Comparison between fracture criteria and experimental results

\section{CRACK RELATIVE DISPLACEMENT FACTOR ESTIMATION BY DIGITAL IMAGE CORRELATION}

$\mathrm{I}$ $\mathrm{n}$ the present paper, the fracture process was evaluated trough two parameters, the Stress Intensity Factor and the Crack Relative Displacement Factor (CRDF), respectively. As shown above, the calculation of SIF is most often based on the analytical solutions. The analysis of the analytical equations allowing calculation the SIF shows that its estimation depends on sample geometry and the loading amplitude.

Based on the displacement fields amplitude the CRDF can be related with the kinematic state near the crack tip [19, 20, 25]. In this case, the CRDF can be calculated from the displacement fields measured by optical metrologies [19, 20, 25]. In the present paper, we propose to use the Digital Image Correlation (DIC) in order to measure the displacement fields and to evaluate the CRDF. It should be added that the evaluation of CRDF allows to separate the mixed mode loading configurations and to identify the part of each mode in the fracture process.

\section{Principle of Digital Image Correlation}

As mentioned above, in the present study, the CRDF was investigated by means DIC. Using this optical full field method the evolution of displacement fields was recorded during the fracture test.

Now concerning the principle of DIC, it is important to specify that this technique is based on comparison of two images acquired before and after sample deformation [29-31, 42]. As described in Fig. 6, the displacement was calculated in the Zone Of Interest (ZOI) meshed by small groups of pixels, called subsets [19, 20, 29-31, 51]. According with the DIC hypothesis, the light intensity distribution during the test does not change. By supposing that the displacements may be approximated as homogeneous and bilinear inside the subset, the displacement fields were estimated by searching the subset distortions in terms of translations, rotations and rigid body motions. In fact, the displacement field represents the displacement vectors of the center of gravity of all subsets.

Concerning the sample preparation, it should be noted that prior to testing, a very thin black and white speckle pattern was sprayed on the specimen surface. Then, as had been indicated above the displacement fields are calculated by tracking the deformation of a random grey speckle pattern applied to sample surface.

In the present study, the ZOI was meshed by using the $32 \times 32$ pixels $^{2}$ subset sizes. The optical device configuration used in the present study consist of an AVT Marlin F-201B with a Pentax 12.5-75 mm lens and a LED light source. The measurement was realized using an Aramis a non-contact and material-independent measuring system based on digital image correlation. The image analysis was performed using Correla software's, developed by PEM team of Pprim Institut of Poitiers [38-39]. The estimating uncertainty of displacement is about 0.026 pixels. 


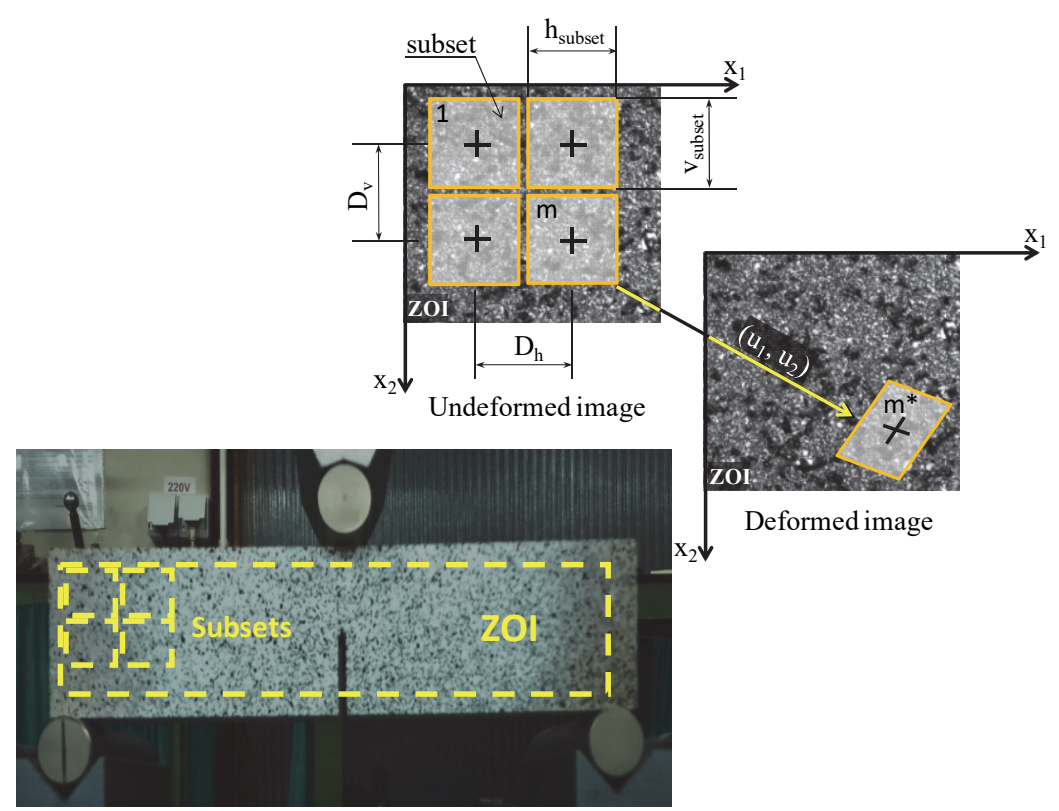

Sample with Black and white speckle pattern

Figure 6: Principle of DIC

\section{Evaluation of crack relative displacement factor}

As detailed in works of $[19,20,25,52]$, the CRDF is calculated from the experimental displacement field via an adjustment procedure based on an iterative Newton-Raphson algorithm (see Fig. 7).

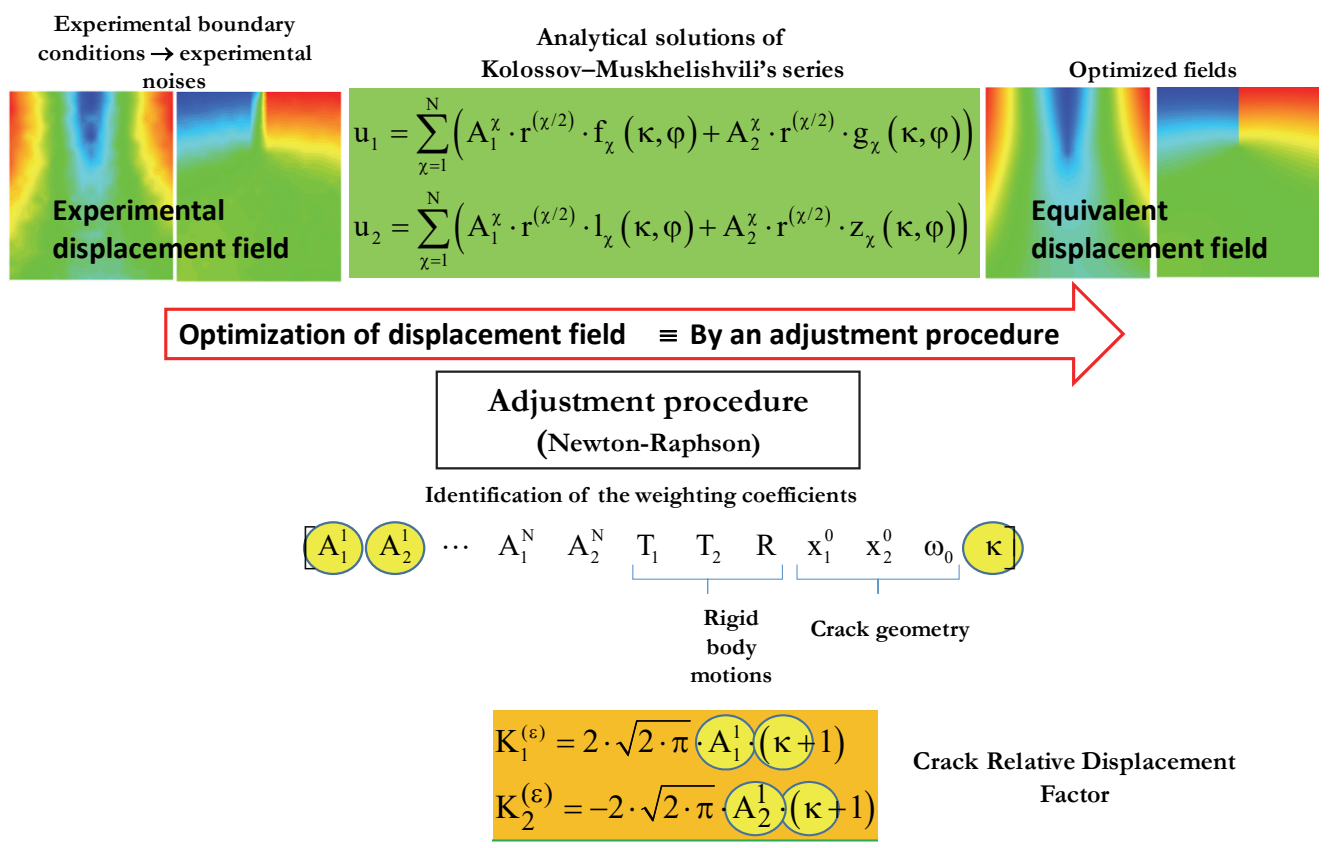

Figure 7: Methodology of CRDF calculation.

This consists in a fitting of analytical solutions of Kolossov-Muskhelishvili's series [53,54] on the displacement fields measured by DIC. Dubois et al. [16, 17], Pop et al. [19] and Meite et al. [20] show that by using this approach, an "equivalent" displacement field can be created without experiment noises, the knowledge of the material properties or the nonlinear phenomena presence [17-20]. Then, the CRDF can be expressed as a function to the weighting coefficients of the analytical solutions of Kolossov-Muskhelishvili's series. 
The mean value of CRDF calculated for maximum loading given in Tabs. 1 and 2, calculated from Pop et al. [19] and Meite et al. [20] developments are resumed in Tabs. 3 and 4 . The values of the weighting coefficients associated with opening and shear modes are also summarized in Tabs. 3 and 4. The weighting coefficients were estimated according with the methodology illustrated in Fig. 7.

\begin{tabular}{|c|c|c|c|c|c|c|}
\hline Specimens & $\begin{array}{c}\mathrm{A}_{1}{ }^{1} \\
{\left[\mathrm{~m}^{0.5}\right] \times 10^{-3}}\end{array}$ & $\begin{array}{c}\text { Mean CRDF } \\
\text { Mode I }\left(K_{I}^{\varepsilon}\right) \\
{\left[\mathrm{m}^{0.5}\right] \times 10^{-3}}\end{array}$ & $\begin{array}{c}\mathrm{A}_{2}{ }^{1} \\
{\left[\mathrm{~m}^{0.5}\right] \times 10^{-3}}\end{array}$ & $\begin{array}{c}\text { Mean CRDF } \\
\text { Mode I }\left(K_{I I}^{E}\right) \\
{\left[\mathrm{m}^{0.5}\right] \times 10^{-3}}\end{array}$ & $\left(K_{I}^{\varepsilon}\right) /\left(K_{I I}^{\varepsilon}\right)$ & $\begin{array}{c}\left(K_{I}\right) /\left(K_{I I}\right) \\
\text { Tab. } 1\end{array}$ \\
\hline I.1-6 & 9.8 & 0.138 & 0.07 & 0.001 & 125 & / \\
\hline I. $7-14$ & 7.2 & 0.102 & 0.05 & 0.0008 & 127 & / \\
\hline
\end{tabular}

Table 3: Single Edge Notch Bend Test- Crack Relative Displacement Factor

\begin{tabular}{ccccccc}
\hline Specimens & $\begin{array}{c}\mathrm{A}_{1}{ }^{1} \\
{\left[\mathrm{~m}^{0.5}\right] \times 10^{-3}}\end{array}$ & $\begin{array}{c}\text { CRDF } \\
\text { Mode I }\left(K_{I}^{\varepsilon}\right) \\
{\left[\mathrm{m}^{0.5} \times 10^{-3}\right.}\end{array}$ & $\begin{array}{c}\mathrm{A}_{2}{ }^{1} \\
{\left[\mathrm{~m}^{0.5}\right] \times 10^{-3}}\end{array}$ & $\begin{array}{c}\text { CRDF } \\
\text { Mode II }\left(K_{I I}{ }^{\varepsilon}\right)\end{array}$ & $\begin{array}{c}\left(K_{I}^{\varepsilon}\right) /\left(K_{I I}{ }^{\varepsilon}\right) \\
{\left[\mathrm{m}^{0.5} \times \times 10^{-3}\right.}\end{array}$ & $\begin{array}{c}\left(K_{I}\right) /\left(K_{I I}\right) \\
\text { Tab. } 2\end{array}$ \\
II.1-5 & 0.8 & 0.012 & 7.5 & 0.105 & 0.11 & 0.18 \\
II.6-10 & 2.3 & 0.032 & 10 & 0.142 & 0.23 & 0.24 \\
\hline
\end{tabular}

Table 4: Compact Shear Test- Crack Relative Displacement Factor

The data resumed in Tabs. 3 and 4 lead us conclude that the opening and shear modes coexist during the test. The crack path observed after the tests indicated that the crack is not rectilinear. This aspect may be connected with the experimental boundary conditions and the PB fiber orientation.

It is also interesting to observe that the relationship between the CRDF corresponding to mode I and II, and the relationship to the SIF show some similarities.

Pop et al $[19,20]$ and Meite et al. $[25,52]$ show also that the energy may be estimated from the CRDF and SIF values, Eq. (6).

$$
G_{F}=\frac{K_{\gamma}^{(\varepsilon)} \cdot K_{\gamma}^{(\sigma)}}{8}
$$

where:

$$
K_{\gamma}^{(\varepsilon)}=A_{\gamma}^{1}(k+1) \sqrt{8 \pi}
$$

where $K_{\gamma}^{(\varepsilon)}$ is the Crack Relative Displacement Factor; $K_{\gamma}^{(\sigma)}$ is the Stress Intensity Factor and $\gamma=1$ or 2 corresponds to mode 1 and mode $2 ; A_{1}^{i}, A_{2}^{i}$ are the weighting coefficients associated with opening and shear modes. Tab. 5 resumed the values of the energy release rate calculated from the results obtained in the Tab. 1-4.

\begin{tabular}{ccc}
\hline Specimens & $\begin{array}{c}\text { Energy release } \\
\text { rate } \\
\text { Mode I } \\
{\left[\mathrm{J} / \mathrm{m}^{2}\right]}\end{array}$ & $\begin{array}{c}\text { Energy release } \\
\text { rate } \\
\text { Mode II } \\
{\left[/ \mathrm{m}^{2}\right]}\end{array}$ \\
I.1-6 & 15.3 & $/$ \\
I.7-14 & 9.8 & $/$ \\
II.1-5 & 0.16 & 8.2 \\
II.6-10 & 0.73 & 13.5 \\
\hline
\end{tabular}

Table 5: Energy values. 


\section{CONCLUSIONS}

7 he paper presents the experimental results for mechanical and fracture properties of particleboard materials. Tab. 6 summarizes the obtained results for the two PB thicknesses corresponding to direction 2 of orientation. It could be observed that the PB with thickness of $16 \mathrm{~mm}$ has higher mechanical properties (Modulus of Rupture-MOR and Modulus of Elasticity-MOE); while the higher fracture toughness was obtained for PB with $25 \mathrm{~mm}$ thickness.

\begin{tabular}{ccccc}
\hline Thickness & $\begin{array}{c}\text { MOR } \\
{[\mathrm{MPa}]}\end{array}$ & $\begin{array}{c}\mathrm{MOE} \\
{[\mathrm{MPa}]}\end{array}$ & $\begin{array}{c}K_{I C} \\
{\left[\mathrm{MPa} \cdot \mathrm{m}^{1 / 2}\right]}\end{array}$ & $\begin{array}{c}K_{\text {eff }} \\
{\left[\mathrm{MPa} \cdot \mathrm{m}^{1 / 2}\right]}\end{array}$ \\
16 & 9.30 & 1406.7 & 0.736 & 0.631 \\
25 & 9.24 & 1153.2 & 0.841 & 0.785 \\
\hline
\end{tabular}

Table 6: A comparison of mechanical and fracture properties for PB

Using the experimental displacements measured by Digital Image Correlation (DIC) the Crack Relative Displacement Factor (CRDF) was estimated. The evaluation of CRDF allowing to evaluate the part of each mode in the fracture process. According to presented approach, all changes in material properties can be directly correlated with the displacement measurement and implicitly with the CRDF amplitude. As shown, the calculation of CRDF may be performed without knowledge of the material constitutive law.

The values of CRDF show that even for an opening mode loading, the crack path and experimental boundary conditions induce a mixed mode configuration. Even if the value of CRDF corresponding to mode II is small, the results show the presence of the mode II during the crack propagation in opening mode.

As shown in Tab. 4, the relationship between the CRDF corresponding to mode I and II of fracture, and the relationship between the Stress Intensity Factor (SIF) show some similarities to the shear test. This observation allows consideration of the calculated phase angle.

Moreover, the fracture energy was evaluated from the CRDF and the SIF values. It should be noted that this approach allows evaluation of the fracture parameters without the knowledge of the properties of material.

Classical fracture criteria (Maximum Tensile Stress and Minimum Strain Energy Density) provide a good prediction of fracture of particleboard (see Fig. 5).

\section{ACKNOWLEDGEMENT}

$\mathrm{P}$ art of the experimental work was carried out in the framework of the grant from the Romanian National Authority for Scientific Research, CNCS - UEFISCDI, project code PN-III-P1-1.1-MCD-2016-0076, contract number 41/8.11.2016, which supports the mobility of Dr. Pop at the University Politehnica Timișoara. The authors are grateful to Mr. Robert Moscaliuc for specimen preparation and his contribution to experimental program.

\section{REFERENCES}

[1] Beer, P., Sinn, G., Gindl, M., Stanzl-Tschegg, S. (2005). Work of fracture and of chips formation during linear cutting of particle-board, Journal of Materials Processing Technology 159, pp. 224-228.

[2] Beer, P., Gindl, M., Stanzl-Tschegg, S. (2008). Wedge splitting experiments on three-layered particleboard and consequences for cutting, Holz als Roh- und Werkstoff 66, pp. 135-141.

[3] ANSI A208.1 (1998). Particleboard and MDF For Shelving, American National Standard, Composite Panel Association, Gaithersburg, MD.

[4] Johnson, J. A., Ifju, G., Rogers, H.W. (1976). The performance of composite wood/particleboard beams under two point loading, Wood and Fiber, 8(2), pp. 85-97.

[5] Norvydas, V., Minelga, D. (2006). Strength and Stiffness Properties of Furniture Panels Covered with Different Coatings, Materials Science, 12(4), pp. 328-332. 
[6] Kulman, S., Boyko L., Antsyferova, A. (2015) Bending strength (modulus of rupture) and modulus of elasticity of MDF different density at various temperature, Annals of Warsaw University of Life Sciences - Forestry and Wood Technology, 91, pp. 101-106.

[7] Stanzl-Tschegg, S.E., Navi P. (2009). Fracture behaviour of wood and its composites. A review. Holzforschung 63, pp. 139-149.

[8] Ilcewicz, L.B. (1979). On the phenomena of fracture in particleboard, Oregon State University.

[9] Veigel, S., Rathke, J., Weigl, M., Gindl-Altmutter, W. (2012). Particle Board and Oriented Strand Board Prepared with Nanocellulose-Reinforced Adhesive, Journal of Nanomaterials, Article ID 158503, 1-8.

[10] Marsavina, L., Pop, O., Linul, E. (2018). Mixed mode fracture toughness of particleboard, Proceedia Stuctural Integrity, 9, pp. 47-54.

[11] Matsumoto, N., Nairn, J.A. (2007). Fracture Toughness of MDF and other Materials with Fiber Bridging, Proc. of 22nd Ann. Tech. Conf. of the Amer. Soc. of Composites, Sept. 17-19, Seattle, WA, pp. 1-19.

[12] Niemz, P., Diener, M., and Pöhler, E. (1997). Untersuchungen zur Ermittlung der Bruchzähigkeit an MDF-Platten, Holz als Roh- und Werkstoff, 55, pp. 327-330.

[13] Yoshihara, H. (2010) Mode I and mode II initiation fracture toughness and resistance curve of medium density fiberboard measured by double cantilever beam and three-point bend end-notched flexure tests, Engineering Fracture Mechanics, 77, pp. 2537-2549

[14] Sneddon, IN., (1946) The distribution of stress in the neighbourhood of a crack in an elastic solid, Proc R Soc Lond, Ser A Math Phys Sci 187, 229-260.

[15] Irwin, GR. (1957) Analysis of stresses and strains near the end of a crack traversing a plate, J Appl Mech, 24, 361-364.

[16] Erdogan, F. (1962) On the stress distribution in plates with collinear cuts under arbitrary loads, In: Proceedings of the fourth US national congress of applied mechanics, 1, 547-574.

[17] Dubois, F., Chazal, C. and Petit, C. (2002) Viscoelastic crack growth process in wood timbers: an approach by the finite element method for mode I fracture, Int J Fract, 113, 367-388.

[18] Dubois, F. and Petit, C. (2005) Modeling of the crack growth initiation in viscoelastic media by the G $\theta$ integral, Eng Fract Mech, 72, 2821-2836.

[19] Pop. O., Meite, M., Dubois, F. and Absi, J. (2011) Identification algorithm for fracture parameters by combining DIC and FEM approaches, International Journal of Fracture, 170, 101-114.

[20] Méité, M., Pop, O., Dubois F. and Absi, J. (2013) Characterization of mixed-mode fracture based on a complementary analysis by means of full-field optical and finite element approaches, International Journal of Fracture, 180, 41-52.

[21] Cherepanov, G. (1967) Crack propagation in continuous media, J Appl Mech, 31, 476-488.

[22] Budiansky, E. and Rice, J. (1973) Conservation laws and energy release rates, J Appl Mech, 40, 201-203.

[23] Rice, J. (1968) A path independent integral and the approximate analysis of strain concentration by notched and cracks, J Appl Mech, 35, 379-386.

[24] Pop, O., Dubois, F. and Absi, J. (2013) J-integral evaluation in cracked wood specimen using the mark tracking method, Wood Science and Technology, 47 (2), 257-267.

[25] Jamaaoui, A., Pop, O., Dubois, F. and Costa, G. (2017) Wedge Splitting Test on Douglas genotypes using an integrated mixed-mode approach, Theoretical and Applied Fracture Mechanics, 91, 44-51.

[26] Post, D. (1993) Moire interferometry. In: Kobayashi AS, editor. Handbook on experimental mechanics, New York.

[27] Orteu, JJ. (2009) 3-D computer vision in experimental mechanics, Optics and Lasers in Engineering, 47:282-291.

[28] Wells, A. and Post, D. (1958) The dynamic stress distribution surrounding a running crack-a photoelastic analysis, Proc Soc Exp Stress Anal, 16, 69-92

[29] Sutton, M.A., Wolters, W.J., Peters, W.H., Ranson, W.F. and McNeil, S.R. (1983) Determination of Displacements Using an Improved Digital Correlation Method, Image and Vision Computating, 1(3), 133-139.

[30] Sutton, M.A., Cheng, M.Q., Peters, W.H., Chao, Y.J. and McNeill, S.R. (1986) Application of an Optimized Digital Correlation Method to Planar Deformation Analysis, Image and Vision Computing, 4(3), 143-151

[31] Sutton, M.A., Yan, J.H., Tiwari, V., Schreier, H.W. and Orteu, J.J. (2008) The effect of out-of-plane motion on 2D and 3D digital image correlation measurements, Optics and Lasers in Engineering, 46(10), 746-757 .

[32] Brémand, F., Dupré, J. and Lagarde, A. (1995) Mesure des déformations sans contact par analyse d’images, Photomécanique 95 - Etude du comportement des matériaux et des structures, Ed. Eyrolles, 171-177.

[33] Bretagne, N., Valle, V. and Dupre, J.C. (2005) Development of the marks tracking technique for strain field and volume variation measurements, NDT\&E International, 38, 290-298.

[34] Dupré, J.C., Doumalin, P., Belrhiti, Y., Khlifi, I., Pop, O. and Huger, M. (2018) Detection of cracks in refractory materials by an enhanced digital image correlation technique, Journal of Materials Science, 53 (2), 977-993. 
[35] Belrhiti, Y., Dupre, J.C., Pop, O., Germaneau, A., Doumalin, P., Huger, M and, Chotard, T. Combination of Brazilian test and digital image correlation for mechanical characterization of refractory materials (2017) Journal of the European Ceramic Society, 37 (5), 2285-2293.

[36] Bourdin, F., Stinville, J.C., Echlin, M.P., Callahan, P.G., Lenthe, W.C., Torbet, C.J., Texier, D., Bridier, F., Cormier, J., Villechaise, P., Pollock, T.M. and Valle, V. (2018) Measurements of plastic localization by heaviside-digital image correlation, Acta Materialia, 157, 307-325.

[37] Valle, V., Bokam, P., Germaneau, A. and Hedan, S. (2018) New Development of Digital Volume Correlation for the Study of Fractured Materials, Experimental Mechanics, 1-15. Article in Press.

[38] Brémand, F., Cottron, M., Doumalin, P., Dupré, J.C., Germaneau, A., Valle, V. Mesures en mécanique par méthodes optiques, Techniques de l'Ingénieur, R1850 V2, 1-26.

[39] Belrhiti, Y., Gallet-Doncieux, A., Germaneau, A., Doumalin, P., Dupre, J.C., Alzina, A., Michaud, P., Pop, I.O., Huger, M., Chotard, T. (2012) Application of optical methods to investigate the non-linear asymmetric behavior of ceramics exhibiting large strain to rupture by four-points bending test, Journal of the European Ceramic Society, 32, 4073-4081.

[40] EN 310:1993. Wood-based panels. Determination of modulus of elasticity in bending and of bending strength.

[41] Linul, E., Marsavina, L., Sadowski T., Kneć, M. (2012) Size effect on fracture toughness of rigid polyurethane foams, Solid State Phenomena, 188, 205-210.

[42] Marsavina, L. and Linul, E., Fracture toughness of polyurethane foams. Experimental versus micromechanical models, 18th European Conference on Fracture: Fracture of Materials and Structures from Micro to Macro Scale, ECF 2010; Dresden; Germany; 30 August - 3 September 2010; Code 93905

[43] Marsavina, L., Constantinescu, D.M., Linul, E. et al. (2015) Shear and mode II fracture of PUR foams, Engineering Failure Analysis, 58, 465-476.

[44] Petrova, V., Marsavina, L., Sadowski, T. (2012). Revisit of compact mode II crack specimen. Analysis and fracture interpretation, Theoretical and Applied Fracture Mechanics, 59(1), pp. 41-48.

[45] Aliha, M.R.M., Linul, E., Bahmani, A., Marsavina, L. (2018) Experimental and theoretical fracture toughness investigation of PUR foams under mixed mode I+III loading, Polymer Testing, 67, pp. 75-83.

[46] Erdogan, F., Sih, G.C. (1963). On the crack extension in plates under plane loading and transverse shear, Journal of Basic Engineering, 85, pp. 519-525.

[47] Marsavina, L., Constantinescu, D.M., Linul, E., Stuparu, F.A., Apostol, D.A. (2016) Experimental and numerical crack paths in PUR foams, Engineering Fracture Mechanics, 167, pp. 68-83.

[48] Hussain, M.A., Pu, S.L., Underwood J. (1974) Strain energy release rate for a crack under combined mode I and mode II. In: Fracture analysis, Paris PC, G.R. Irwin GR Editors, ASTM STP560, Philadelphia, pp. 2-28.

[49] Sih, G.C. (1974). Strain-energy-density factor applied to mixed mode crack problems, International Journal of Fracture, 10, pp. 305-321.

[50] Marsavina, L., Berto, F., Negru, R., Serban, D.A., Linul, E. (2017) An engineering approach to predict mixed mode fracture of PUR foams based on ASED and micromechanical modeling, Theoretical and Applied Fracture Mechanics, 91, pp. 148-154.

[51] Hild, F. and Roux, S. (2006) Measuring stress intensity factors with a camera: integrated digital image correlation (IDIC), Comptes Rendus Mécanique, 334, 8-12.

[52] Jamaaoui, A., Pop, O., Ktari, R., Millien, A. and Petit, C. (2017) Analyzing of wedge splitting test on asphalt pavement using optical measurements, Journal of Testing and Evaluation, 45 (6), 1959-1970

[53] Williams, M. (1957) On the stress distribution at the base of a stationary crack, ASME Journal Applied Mechanics 24, 109-114.

[54] Muskhelishvili, IN. (1933) Some basic problem of mathematical theory of elasticity, English translation, Noordhoff. 